\title{
Protection and control of microgrids using dynamic state estimation
}

\author{
Y. Liu ${ }^{1 *}$ (D, A. P. Meliopoulos ${ }^{2}$, L. Sun ${ }^{2}$ and S. Choi ${ }^{2}$
}

\begin{abstract}
High penetration of Converter Interfaced Generations (CIGs) presents challenges in both microgrid ( $\mu$ Grid) circuit and other system with CIG resources, such as wind farms and PV plants. Specifically, protection challenges are mainly brought by the insufficient separation between fault and load currents, especially for $\mu$ Grids in islanded operation, and the short connection length in $\mu$ Grids. In addition, CIG resources exhibit limited inertia and weak coupling to any rotating machinery, which can result in large transients during disturbances. To address the above challenges, this paper proposes a Dynamic State Estimation (DSE) based algorithm for protection and control of systems with substantial CIG resources such as a $\mu \mathrm{Grid}$. It requires a high-fidelity dynamic model and time domain (sampled value) measurements. For $\mu$ Grid circuit protection, the algorithm dependably and securely detects internal faults by checking the consistency between the circuit model and available measurements. For CIG control, the algorithm estimates the frequency at other parts of a $\mu$ Grid using CIG local information only and then utilizes it to provide supplementary feedback control. Simulation results prove that DSE based protection algorithm detects internal faults faster, ignores external faults and has improved sensitivity towards high impedance faults when compared to conventional protection methods. DSE based CIG control scheme also minimizes output oscillation and transient during system disturbances.
\end{abstract}

Keywords: Converter interfaced generation (CIG), Dynamic state estimation (DSE), $\mu$ Grid protection

\section{Introduction}

There exists increasing penetration of renewables in modern power systems. The renewable generating units, including wind turbines, photovoltaic cells, etc., are commonly connected to the grids via converter interfaces, and thus are referred as Converter Interfaced Generations (CIGs). Large numbers of CIGs can be integrated within $\mu$ Grids to minimize the impact on the main grid [1-3]. However, this brings challenges on the protection of $\mu$ Grids against faults and the control of CIGs. Details of the above two challenges are described in the following sections.

\subsection{Protection of $\mu$ Grid circuits}

The protection challenge is brought by the following characteristics of the $\mu$ Grids with CIGs: (a) bi-directional power flow introduced by CIGs; (b) significant difference between the fault current characteristics in grid-connected mode

\footnotetext{
* Correspondence: liuyu@shanghaitech.edu.cn

${ }^{1}$ School of Information Science and Technology (SIST), ShanghaiTech

University, Shanghai 201210, China

Full list of author information is available at the end of the article
}

and in islanded mode; (c) short connection length under protection; and (d) frequent output change from the intermittent generations.

Specifically, legacy protection schemes, e.g. overcurrent protection, distance protection, and differential protection, will encounter different limitations in protecting $\mu$ Grids.

For overcurrent protection, directional elements are required considering the bi-directional power flow of $\mu$ Grids. However, it is almost impossible to provide required selectivity because: (a) fault current may change due to connectivity changes of CIGs; (b) fault current variation within a $\mu$ Grid is limited; and (c) fault current is comparable to load current when the fault current is contributed only by CIGs.

For distance protection, the limitation comes from the short length of the connection lines, resulting in uncertain characteristics of the relay. The relay can easily fail to operate due to the calculated impedance error brought by (a) the sequence model approximation of distance relays, (b) significant difference between the fault current contributed 
by the main grid and the CIGs during grid-connected mode, and (c) the impact of grounding impedance on the relay algorithm.

Differential protection is one of the most effective schemes in protecting $\mu$ Grid circuits, in which the zero sum of currents at both terminals of the line is tested. The sensitivity could be further improved with the use of negative or zero sequence currents. However, it still has limitations in detecting high impedance faults.

To overcome above limitations, researchers have also proposed several new methods. In [4], an adaptive protection scheme with $\mu$ Grid central protection unit is proposed. The method updates settings of overcurrent relays and adjusts coordination among relays according to operating conditions of CIGs and the topology of the $\mu$ Grid. However, the method does not consider variable fault current level due to output change of CIGs. In addition, it needs a sophisticated communication network between the central protection unit and all relays/CIGs. In [5], a protection strategy using microprocessor-based relays for a low-voltage $\mu$ Grid is proposed, which does not require communication nor adaptive protection. However, its sensitivity is poor when applied to short lines and it may trip internal faults with a long delay. In [6], differential protection and the comparative voltage protection are utilized as the main and backup protection functions. However, the method may not be able to detect high impedance faults where the differential current is less than $10 \%$ of the nominal current. In [7], a differential energy based protection scheme is proposed. However, the effectiveness of the scheme highly depends on user-selected settings.

\subsection{Control of CIGs}

Conventional power systems are mainly powered by directly connected synchronous generators, where the load/generation balance is ensured by controlling the frequency of the synchronous generator. Also, the variations of frequency and phase angle are relatively small and slow due to high moment of inertia. For a $\mu$ Grid with high penetration of CIGs, the frequency is irrelevant to the load/generation balance [8], and CIGs do not naturally exhibit inertia [9]. Therefore during disturbances, the output of CIGs may severely oscillate, causing damage or shutdown of the converters.

To solve the above problems, researchers have proposed control schemes to mimic frequency and inertial response for CIGs $[10,11]$. There are limitations to these schemes as the equivalent torques and inertia are greatly related to electric currents which are limited by the converters. Thus, these schemes may be weakened from the fact that the fault current level of CIGs (typically less than $160 \%$ of rated current for short durations and less than $120 \%$ for longer durations [12]) is much smaller compared to the fault current level of conventional synchronous generators (500\% 1000\% of rated current). Researchers have also proposed some additional control schemes based on local information without the need for communication, including the two-axis and three-axis based converter control schemes [13-15]. However, they may not be able to follow the frequency variation of the rest of the $\mu \mathrm{Grid}$ resulting in large output oscillation. Therefore, it is necessary to develop an algorithm that is based on local information only but also has the capability to access the information of the other parts of the $\mu$ Grid without communication channels.

\subsection{Proposed method}

A Dynamic State Estimation (DSE) based algorithm [16-18] is proposed in this paper to solve the above protection and control problems. The algorithm estimates the states of the components of interest using available sampled measurements and a high-fidelity dynamic model, so that the electrical transients can be accurately captured. This feature of the DSE algorithm enables more dependable and secure protection and control of $\mu$ Grid components. Specifically, for protection application, the estimated states are utilized to check consistency between the measurements and the model, and a trip signal is issued if any inconsistency is detected. For control application, the estimated states are utilized to first calculate the remote side frequency information and then this information is adopted to provide a supplementary feedback control to the CIG controller.

The rest of the paper is arranged as follows. Section 2 introduces the DSE based algorithm and its application on protection and control of $\mu$ Grids. Section 3 provides the simulation results for $\mu$ Grid protection and Section 4 demonstrates the results for CIG control. Finally, Section 5 concludes the paper.

\section{Methods}

\subsection{DSE based algorithm and its applications}

The DSE based algorithm requires a high fidelity dynamic model of the components of interest. To build an object-oriented algorithm that works for all components, a standard Algebraic Quadratic Companion Form (AQCF) syntax is briefly introduced (details can be found in [16]). The DSE algorithm is then introduced with the model in AQCF syntax. Finally, the application details on $\mu$ Grid protection and CIG control are provided.

\subsection{AQCF syntax}

The physical laws that the components of interest obey can be described via a set of algebraic and differential equations. These equations are further quadratized by introducing additional variables to make sure that the highest order of nonlinearities is less than or equal to two. For any device, the equations can be written in the 
following device Quadratized Dynamic Model (QDM) syntax, where $\mathbf{x}(t)$ and $\mathbf{i}(t)$ represent the state vector and terminal current vector of the component:

$$
\begin{aligned}
& \mathbf{i}(t)=\mathbf{Y}_{e q x 1} \mathbf{x}(t)+\mathbf{D}_{e q x d 1} \frac{d \mathbf{x}(t)}{d t}+\mathbf{C}_{e q c 1} \\
& \mathbf{0}=\mathbf{Y}_{e q x 2} \mathbf{x}(t)+\mathbf{D}_{e q x d 2} \frac{d \mathbf{x}(t)}{d t}+\mathbf{C}_{e q c 2} \\
& \vdots \\
& \mathbf{0}=\mathbf{Y}_{e q x 3} \mathbf{x}(t)+\left\{\begin{array}{c}
\mathbf{x}(t)^{T}\left\langle\begin{array}{c}
\mathbf{F}_{e q x x 3}^{i} \\
\vdots
\end{array}\right) \mathbf{x}(t)
\end{array}\right\}+\mathbf{C}_{e q c 3}
\end{aligned}
$$

An example of a $\mu$ Grid circuit model (cable) in QDM syntax is presented in Appendix.

Equations (1) is then integrated using the quadratic integration method [19] to convert the differential equations into algebraic equations, where the system dynamics are represented in terms of past history terms. This generates the model in device AQCF syntax, where $t_{m}=t-\Delta t$ and $\Delta t$ is the sampling interval:

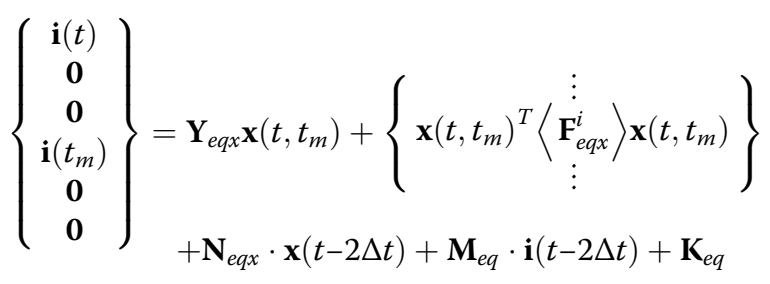

A number of measurements are typically available for the components of interest. Each available measurement can be expressed in terms of the states in (2). This generates the measurement model in AQCF syntax, where $\mathbf{z}\left(t, t_{m}\right)$ is the measurement vector that includes measurements at time $t$ and $t_{m}$,

$$
\begin{aligned}
\mathbf{z}\left(t, t_{m}\right)= & h\left(x\left(t, t_{m}\right)\right)=\mathbf{Y}_{m, x} \mathbf{x}\left(t, t_{m}\right) \\
& +\left\{\begin{array}{c}
\vdots \\
\mathbf{x}\left(t, t_{m}\right)^{T}\left\langle\begin{array}{c}
\mathbf{F}_{m, x}^{i} \\
\vdots
\end{array}\right) \mathbf{x}\left(t, t_{m}\right)
\end{array}\right\} \\
& +\mathbf{N}_{m, x} \cdot \mathbf{x}(t-2 \Delta t)+\mathbf{M}_{m} \cdot \mathbf{i}(t-2 \Delta t)+\mathbf{K}_{m}
\end{aligned}
$$

\subsection{DSE algorithm}

The DSE algorithm executes every two sampling intervals and estimates the states $\mathbf{x}\left(t, t_{m}\right)$ from measurements $\mathbf{z}\left(t, t_{m}\right)$. Here the unconstraint optimization method is utilized,

$$
\operatorname{Min} J=\left(h\left(\mathbf{x}\left(t, t_{m}\right)\right)-\mathbf{z}\left(t, t_{m}\right)\right)^{T} \mathbf{W}\left(h\left(\mathbf{x}\left(t, t_{m}\right)\right)-\mathbf{z}\left(t, t_{m}\right)\right)
$$

where $\mathbf{W}=\operatorname{diag}\left\{1 / \sigma_{1}^{2}, 1 / \sigma_{2}^{2}, \cdots\right\}$, and $\sigma_{i}$ is the standard deviation of measurement $i$.

The best estimation of states $\hat{\mathbf{x}}\left(t, t_{m}\right)$ can be calculated by the iterative algorithm until convergence,

$$
\begin{gathered}
\hat{\mathbf{x}}\left(t, t_{m}\right)^{v+1}=\hat{\mathbf{x}}\left(t, t_{m}\right)^{v}-\left(\mathbf{H}^{T} \mathbf{W} \mathbf{H}\right)^{-1} \mathbf{H}^{T} \mathbf{W}\left(h\left(\hat{\mathbf{x}}\left(t, t_{m}\right)^{v}\right)\right. \\
\left.-\mathbf{z}\left(t, t_{m}\right)\right)
\end{gathered}
$$

where the Jacobian matrix is $\mathbf{H}=\partial h(\mathbf{x}) / \partial \mathbf{x}$.

\subsection{Application details of $\mu \mathrm{Grid}$ circuit protection}

The DSE Based Protection (EBP) determines an internal fault by checking consistency between the measurements and the model. This consistency is evaluated by the confidence level $P_{\text {conf }}(t)$, which can be calculated by,

$$
\begin{aligned}
& P_{\text {conf }}(t)=1-P\left(\zeta(t), m_{v}\right) \\
& \zeta(t)=\hat{\mathbf{s}}\left(t, t_{m}\right)^{T} \hat{\mathbf{s}}\left(t, t_{m}\right) \\
& \hat{\mathbf{s}}\left(t, t_{m}\right)=\sqrt{\mathbf{W}} \cdot \hat{\mathbf{r}}\left(t, t_{m}\right) \\
& \hat{\mathbf{r}}\left(t, t_{m}\right)=h\left(\hat{\mathbf{x}}\left(t, t_{m}\right)\right)-\mathbf{z}\left(t, t_{m}\right)
\end{aligned}
$$

where $P\left(\zeta(t), m_{v}\right)$ is the probability of $\chi^{2}$ distribution given $\chi^{2} \leq \zeta(t)$ with the dimension difference between the measurement and the model as the degrees of freedom, $\hat{\mathbf{r}}\left(t, t_{m}\right)$ is the vector of residuals and $\hat{\mathbf{s}}\left(t, t_{m}\right)$ is the vector of normalized residuals.

The $\mu$ Grid circuit needs to be tripped if there exists an internal fault which is manifested with an inconsistency between the measurements and the model, i.e. the confidence level is low. The EBP relay asserts an internal fault condition when the confidence level which is simply the probability of "lack of fault in the protection zone" goes below $10 \%$, (the $10 \%$ is a user selected cutoff value and has proved to work well). To ensure dependable and secure protection, a user defined intentional delay $\tau_{\text {delay }}$ is introduced to determine the trip decision as:

$$
\operatorname{Trip\_ Decision}(t)=\left\{\begin{array}{l}
1, \text { if } \int_{t-\tau_{\text {rese }}}^{t}\left(1-P_{\text {conf }}(t)\right) d t \geq \tau_{\text {delay }} \\
0, \text { otherwise }
\end{array}\right.
$$

\subsection{Application details of CIG control}

The states of the line connecting the CIG and the rest of the $\mu$ Grid (remote side) are accurately estimated via dynamic state estimator located at the CIG site where only local information is needed. The dynamic state estimation provides the estimated remote side voltages and currents since the circuit AQCF model is part of the dynamic estimation model. The remote side frequency and the rate of frequency change are subsequently calculated 
from the remote side voltages and currents. Finally, a supplementary control scheme is utilized, where the estimated frequency information from the remote side is introduced as inputs. Note that this DSE scheme is based on sampled values so it can accurately capture electrical transients including frequency information. This enables the controller to utilize remote side frequency information without any telemetered data (communications).

The detailed control diagram is shown in Fig. 1. The control input signals (at time $t_{k}$ ) include the frequencies and rates of change of frequency at the local side $\left(f_{\text {local }}\right.$ and $\left.d f_{\text {local }} / d t\right)$ and the remote side $\left(f_{\text {remote }}\right.$ and $\left.d f_{\text {remote }} / d t\right)$, and the real power $\left(P_{m}\right)$ and the reactive power $\left(Q_{m}\right)$. The control output signals (at time $t_{k+1}$ ) include the frequency $f_{c t r l}$, phase angle $\theta_{c t r l}$ and modulation index $m_{c t r l}$, corresponding to the control of the frequency, phase angle and amplitude of the output voltage, respectively. These three output signals are utilized to generate switching sequences as detailed below.

(a) The aim of the frequency control is to make the frequency output $f_{c t r l}\left(t_{k+1}\right)$ track the remote side frequency $f_{\text {remote }}\left(t_{k+1}\right)$, to minimize the oscillation of the angle difference between the two sides. The process first calculates $\Delta \delta_{\text {remote }}\left(t_{k+1}\right)-\Delta \delta_{\text {local }}\left(t_{k+1}\right)$, i.e. the change of the angle difference during the period $\left[t_{k}, t_{k+1}\right]$, and proportional and integral (PI) control is then utilized to calculate the frequency output $f_{c t r l}\left(t_{k+1}\right)$.

(b) The aim of the phase angle control is to make the real power output $P_{m}\left(t_{k+1}\right)$ track the reference power $P_{r e f}\left(t_{k+1}\right)$. This process is implemented via a PI controller.

(c) The aim of the modulation index control is to make the reactive power output $Q_{m}\left(t_{k+1}\right)$ track the reference power $Q_{r e f}\left(t_{k+1}\right)$. This process is also implemented via a PI controller.

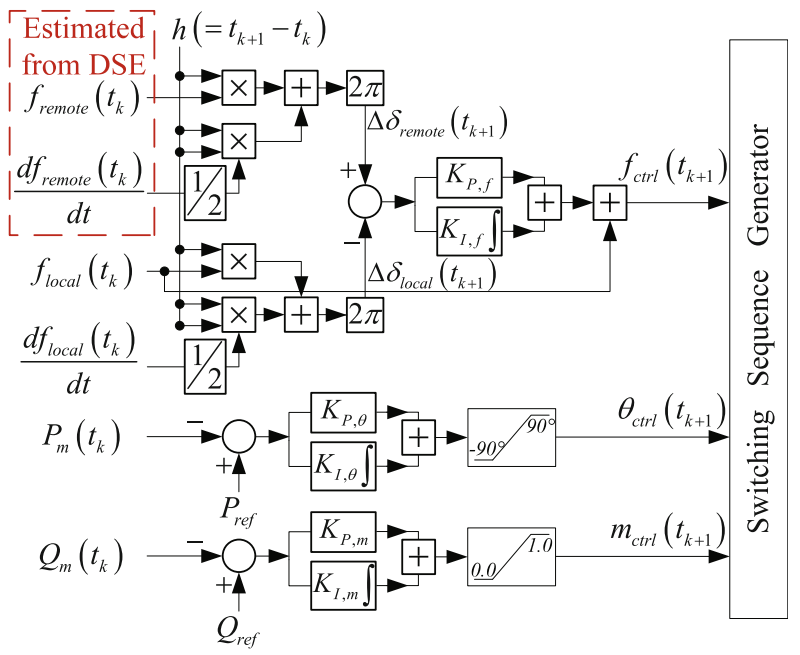

Fig. 1 Detail diagram of CIG control

\section{Results}

\section{1 $\mu$ Grid circuit protection}

The example test system is a $480 \mathrm{~V} \mu$ Grid illustrated in Fig. 2. The $\mu$ Grid is connected to the main grid with a static switch (SS) at the point of common coupling and a $13.8 \mathrm{kV} / 480 \mathrm{~V}$ distribution transformer. There are two distributed generations inside the $\mu \mathrm{Grid}$, including a small wind turbine system and a PV system. Note that both distributed generations are connected to the $\mu$ Grid via converters.

The line under protection is A1-A2, with a length of $330 \mathrm{ft}$, and its cable structure is shown in Fig. 3. The sequence parameters are shown in Table 1, and the series resistance, series reactance and shunt capacitance matrices per unit length are shown in Table 2. Three-phase currents and voltages are measured at both sides of line A1-A2, and the performance of the proposed EBP technique for the protection of the $\mu$ Grid are demonstrated via several events. Note that two legacy relays are considered for comparison, i.e. a distance protection relay (installed at side A2) and a line differential protection relay.

\subsection{Settings of legacy relays}

\subsubsection{Distance relay settings}

Zone 1,2 and 3 of the distance relay are selected as $80 \%, 125 \%$ and $260 \%$ of the positive sequence impedance, respectively. Detail settings are shown in Table 3.

\subsubsection{Line differential relay settings}

Zero-sequence current line differential protection with alpha plane method [20] is used. The restraint region is between $1 / 6$ to 6 , with the total angular extent of $195^{\circ}$. The thresholds are: phase current $144 \mathrm{~A}, 3 \mathrm{I}_{0}$ (zerosequence current) $12 \mathrm{~A}$, and $3 \mathrm{I}_{2}$ (negative-sequence current) $12 \mathrm{~A}$. The relay trips if the current phasor ratio falls outside the restraint region and at least one of the thresholds is exceeded, with a delay of 1 cycle.

\subsubsection{EBP settings}

For consistency, the intentional delay for the EBP relay is selected as $\tau_{\text {delay }}=1$ cycle and the reset time is $\tau_{\text {reset }}=2$ cycles.

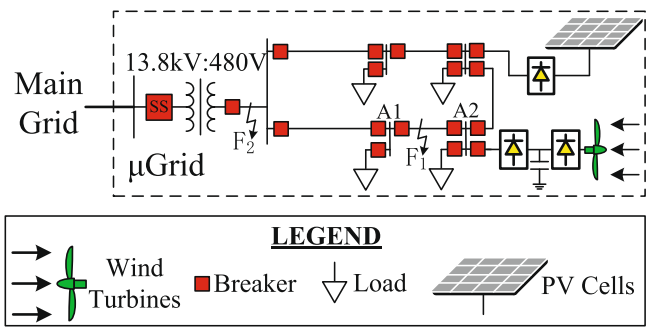

Fig. 2 Example system of $\mu$ Grid circuit protection 


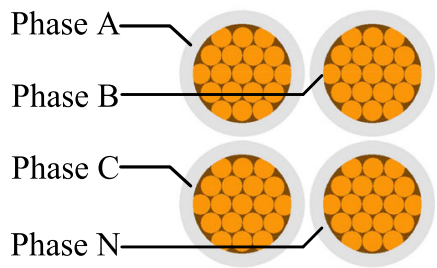

Fig. $3480 \mathrm{~V}$ cable structure

\subsection{Simulation results}

The performance of the proposed EBP scheme and two legacy schemes (distance and line differential protection) is investigated using the following 4 events. Events 1 to 3 are faults when the $\mu$ Grid is in grid-connected mode, whereas event 4 is a fault when the $\mu$ Grid is in islanded mode.

\subsubsection{Event 1: Internal bolted fault, grid-connected mode}

A bolted $(0.01 \Omega)$ phase A to ground fault occurs at $1.4 \mathrm{~s}$ in the middle of line A1-A2. In this event, the $\mu$ Grid is connected to the main grid and the location of the fault is shown as $F_{1}$ in Fig. 2. Three-phase currents and voltages at both sides of A1-A2 are provided in Fig. 4.

\subsubsection{Distance relay}

The calculated impedance trace, superimposed on the relay characteristics, is shown in Fig. 5. As can be seen, the calculated impedance falls outside of the tripping zone. This is mainly due to the large fault current from the grid side and the short length of the cable. Therefore, the distance relay fails to detect this internal fault.

\subsubsection{Line differential relay}

The trace of the zero-sequence current phasor ratio, superimposed on the relay characteristics, is shown in Fig. 6 . Along the trace, the characters ' $x$ ' and 'o' show whether any of the thresholds is exceeded. Prior to the fault, the ratio stays near $(-1,0)$ with no threshold exceeded. During the fault, the ratio enters the trip region one sample after the fault occurrence (at $1.4002 \mathrm{~s}$ ), with the thresholds exceeded. Therefore, the line differential protection trips the line at $1.4169 \mathrm{~s}(1.4002 \mathrm{~s}+1$ cycle of $0.0167 \mathrm{~s})$.

Table 1 Sequence parameters of the $\mu$ Grid circuit under protection

\begin{tabular}{ll}
\hline Parameter & Value \\
\hline Positive (Negative) sequence & $0.08410+j 0.01347 \Omega$ \\
Zero sequence & $0.09409+j 0.26528 \Omega$ \\
\hline
\end{tabular}

Table 2 Series resistance, series reactance and shunt capacitance matrices of the $\mu$ Grid circuit under protection

\begin{tabular}{|c|c|c|c|c|c|}
\hline Parameter & Value & & & & \\
\hline $\begin{array}{l}\text { Series resistance matrix } \\
\text { (per feet) }\end{array}$ & {$\left[\begin{array}{l}0.2649 \\
0.0101 \\
0.0101 \\
0.0101\end{array}\right.$} & $\begin{array}{l}0.0101 \\
0.2649 \\
0.0101 \\
0.0101\end{array}$ & $\begin{array}{l}0.0101 \\
0.0101 \\
0.2649 \\
0.0101\end{array}$ & $\left.\begin{array}{l}0.0101 \\
0.0101 \\
0.0101 \\
0.2649\end{array}\right]$ & $m \Omega / f t$ \\
\hline $\begin{array}{l}\text { Series reactance matrix } \\
\text { (per feet) }\end{array}$ & {$\left[\begin{array}{l}0.7830 \\
0.6817 \\
0.6606 \\
0.6817\end{array}\right.$} & $\begin{array}{l}0.6817 \\
0.7830 \\
0.6817 \\
0.6606\end{array}$ & $\begin{array}{l}0.6606 \\
0.6817 \\
0.7830 \\
0.6817\end{array}$ & $\left.\begin{array}{l}0.6817 \\
0.6606 \\
0.6817 \\
0.7830\end{array}\right]$ & $\mu \mathrm{H} / \mathrm{ft}$ \\
\hline $\begin{array}{l}\text { Shunt capacitance matrix } \\
\text { (per feet) }\end{array}$ & {$\left[\begin{array}{c}0.1431 \\
0 \\
0 \\
0\end{array}\right.$} & $\begin{array}{c}0 \\
0.1431 \\
0 \\
0\end{array}$ & $\begin{array}{c}0 \\
0 \\
0.1431 \\
0\end{array}$ & $\left.\begin{array}{c}0 \\
0 \\
0 \\
0.1431\end{array}\right]$ & $n F / f t$ \\
\hline
\end{tabular}

\subsubsection{EBP relay}

The performance of EBP relay is depicted in Fig. 7 . The first two channels demonstrate the residuals and the normalized residuals of the three-phase currents at side A2. It can be observed that the residuals are small before the fault but become extremely large during the fault. The confidence level in the third channel drops to zero one sample $(208 \mu \mathrm{s})$ after the fault occurrence. The fault is detected at $1.4002 \mathrm{~s}$ and the circuit is tripped (in the fourth channel) at $1.4169 \mathrm{~s}$.

\subsubsection{Summary of event 1}

For this internal bolted phase A to ground fault during the grid-connected mode, the distance relay fails to detect this internal fault, whereas both the line differential relay and the EBP relay detect the fault at $1.4002 \mathrm{~s}$ and trip the fault at $1.4169 \mathrm{~s}$.

\subsubsection{Event 2: Internal high impedance fault, grid-connected} mode

A high impedance (50 $\Omega$ ) phase A to ground fault occurs at the middle of A1-A2 at 1.4 s with the $\mu$ Grid connected to the main grid. The location of the fault is $F_{1}$ as shown in Fig. 2. Three-phase currents and voltages at both sides of A1-A2 are provided in Fig. 8.

Table 3 Distance relay settings

\begin{tabular}{ll}
\hline Function & Settings \\
\hline Line and Ground & $0.0681 \angle 9.10^{\circ} \Omega, 1$ cycle delay, compensation \\
Distance, Zone 1 & factor $k=2.959 \angle 78.63^{\circ}$ \\
Line and Ground & $0.1065 \angle 9.10^{\circ} \Omega, 0.15$ sdelay, compensation \\
Distance, Zone 2 & factor $k=2.959 \angle 78.63^{\circ}$ \\
Line and Ground & $0.2214 \angle 9.10^{\circ} \Omega, 0.5$ sdelay, compensation factor \\
Distance, Zone 3 & $k=2.959 \angle 78.63^{\circ}$ \\
\hline
\end{tabular}




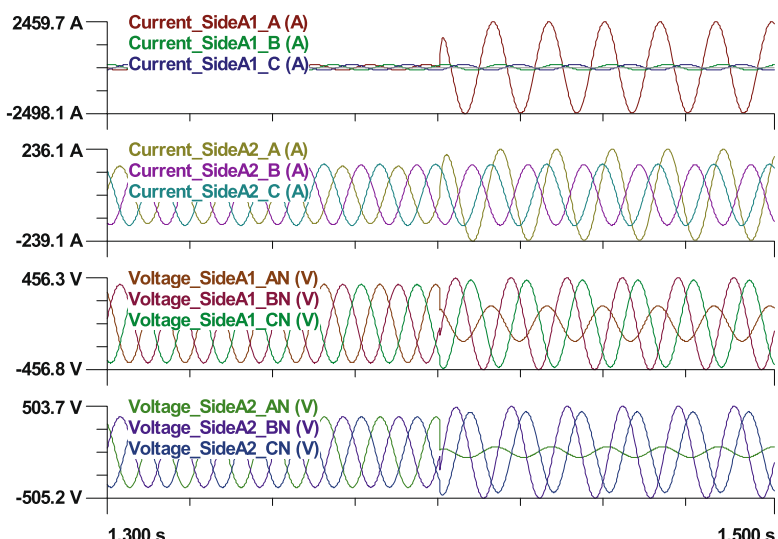

Fig. 4 Three phase currents and voltages of event 1: internal bolted fault, grid-connected mode

\subsubsection{Distance relay}

The calculated impedance trace, superimposed on the relay characteristics, is shown in Fig. 9. As can be seen, the calculated impedance during fault stays close to the value before the fault and falls outside of the tripping zone. This is due to the high fault impedance. Therefore, the distance relay fails to detect this internal fault.

\subsubsection{Line differential relay}

The trace of the zero-sequence current phasor ratio, superimposed on the relay characteristics, is shown in Fig. 10. Prior to the fault, the ratio stays close to $(-1,0)$ with no threshold exceeded. During the fault, the ratio enters the trip region at $1.4161 \mathrm{~s}$, though still no threshold is exceeded. In fact the calculated ' $3 \mathrm{I}_{0}$ ' during the fault is less than 4.5 Amps, which is far less than the threshold setting of 12 Amps. Therefore, the line differential protection also fails to detect this internal fault.

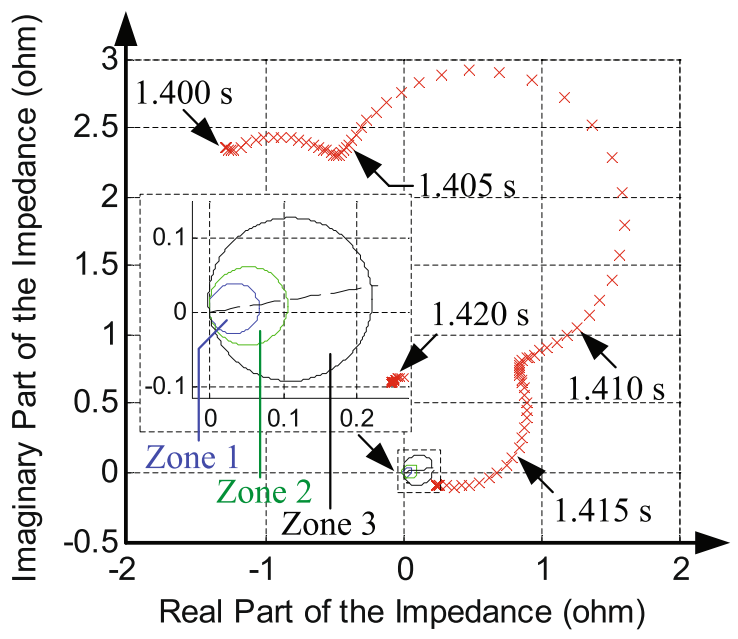

Fig. 5 Calculated impedance trace of event 1: internal bolted fault, grid-connected mode

\subsubsection{EBP relay}

The performance of the EBP relay is depicted in Fig. 11. The confidence level drops to zero one sample after fault occurrence and oscillates during the fault, indicating abnormality of the circuit. The fault is detected at $1.4002 \mathrm{~s}$ and the circuit is tripped at $1.4223 \mathrm{~s}$.

\subsubsection{Summary of event 2}

For this internal high impedance phase A to ground fault during grid-connected mode, both the distance relay and the line differential relay fail to detect this internal fault, whereas the EBP relay detects the fault at $1.4002 \mathrm{~s}$ and the fault is tripped at $1.4223 \mathrm{~s}$.

\subsubsection{Event 3: External bolted fault, grid-connected mode} With the $\mu$ Grid connected to the main grid, a bolted $(0.01 \Omega)$ phase A to ground fault occurs at the secondary side of the transformer at $1.4 \mathrm{~s}$. The location of the fault is shown as $\mathrm{F}_{2}$ in Fig. 2. Three-phase currents and voltages at both sides of A1-A2 are provided in Fig. 12.

\subsubsection{Distance relay}

The calculated impedance trace, superimposed on the relay characteristics, is shown in Fig. 13. As seen, the calculated impedance correctly falls outside of the tripping zone, and therefore, the distance relay will correctly ignore this external fault.

\subsubsection{Line differential relay}

The trace of the zero-sequence current phasor ratio, superimposed on the relay characteristics, is shown in Fig. 14. Prior to the fault, the ratio stays close to $(-1,0)$ with no threshold exceeded. During the fault, although the thresholds are exceeded, the ratio still stays close to $(-1,0)$ inside the restraint zone. Therefore, the line

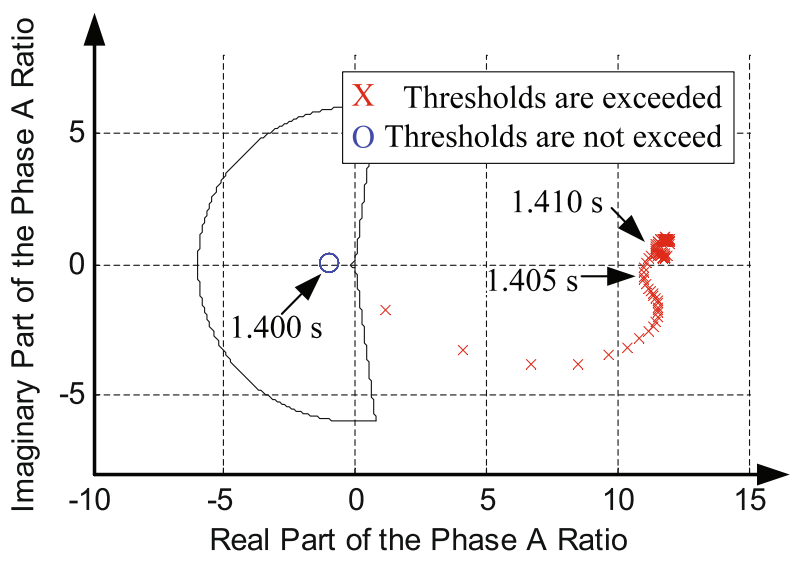

Fig. 6 Calculated current phasor ratio trace of event 1 : internal bolted fault, grid-connected mode 


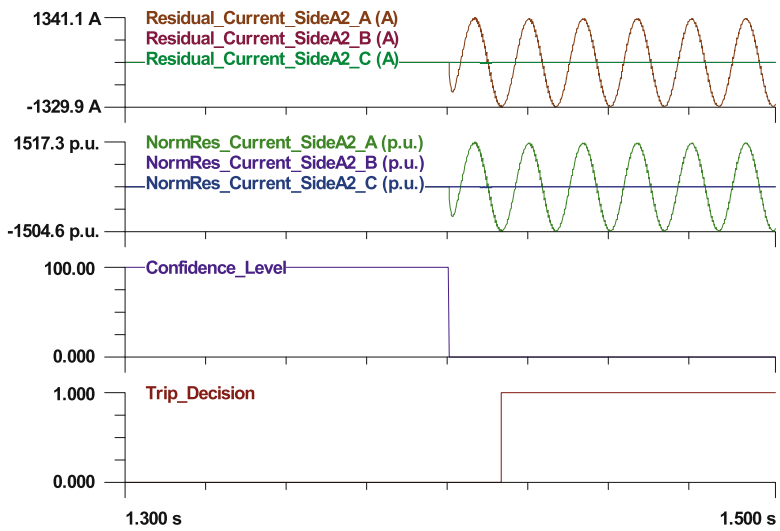

Fig. 7 EBP relay performance of event 1: internal bolted fault, grid-connected mode

differential protection will also correctly ignore this external fault.

\subsubsection{EBP relay}

The performance of the EBP relay is depicted in Fig. 15 . The residuals increase slightly at the beginning of the fault and gradually decrease to the values of normal operating condition. The confidence level remains high during the fault, which indicates that the line under protection is healthy. Therefore, the EBP relay also correctly ignores this external fault.

\subsubsection{Summary of event 3}

For this external bolted phase A to ground fault during the grid-connected mode, the two legacy relays (distance and line differential) as well as the EBP relay all correctly ignore this external fault.

\subsubsection{Event 4: Internal bolted fault, islanded mode}

With the $\mu$ Grid in islanded mode, a bolted $(0.01 \Omega)$ phase $\mathrm{A}$ to ground fault occurs at $1.4 \mathrm{~s}$ at the middle

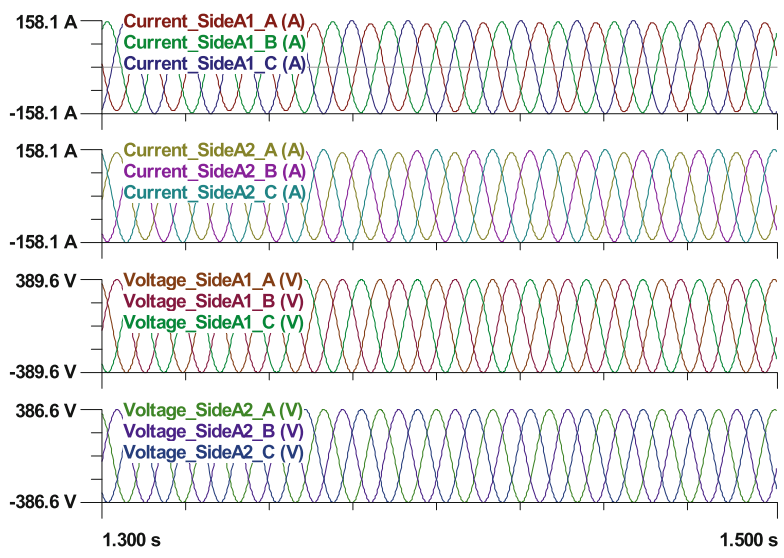

Fig. 8 Three phase currents and voltages of event 2: internal high impedance fault, grid-connected mode

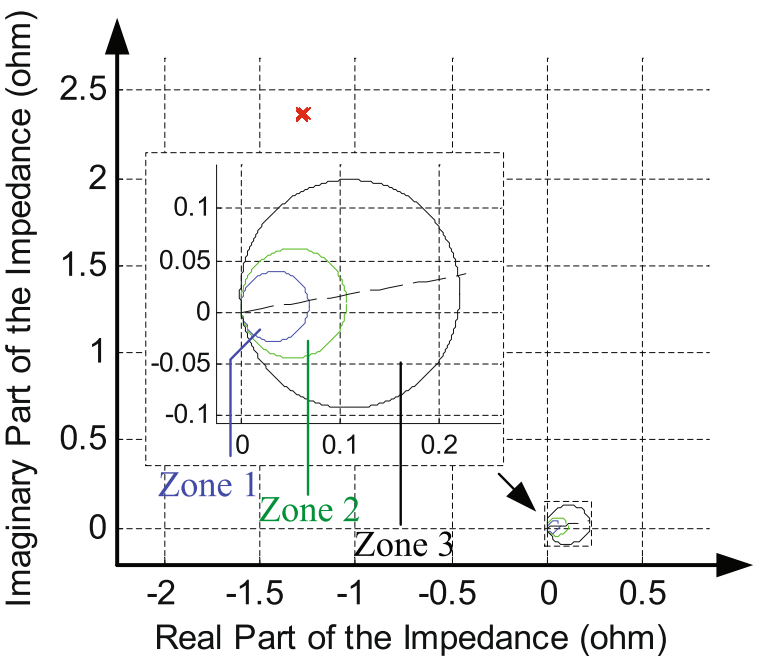

Fig. 9 Calculated impedance trace of event 2: internal high impedance fault, grid-connected mode

of A1-A2, i.e. $F_{1}$ as shown in Fig. 2. Three-phase currents and voltages at both sides of A1-A2 are provided in Fig. 16.

\subsubsection{Distance relay}

The calculated impedance trace, superimposed on the relay characteristics, is shown in Fig. 17. The calculated impedance falls into the tripping zone 2 at $1.420 \mathrm{~s}$, though the impedance should be theoretically inside zone 1 (this bolted fault is within $80 \%$ of the line). This is mainly due to the sequence model approximation of the line and its short length. Therefore, the distance

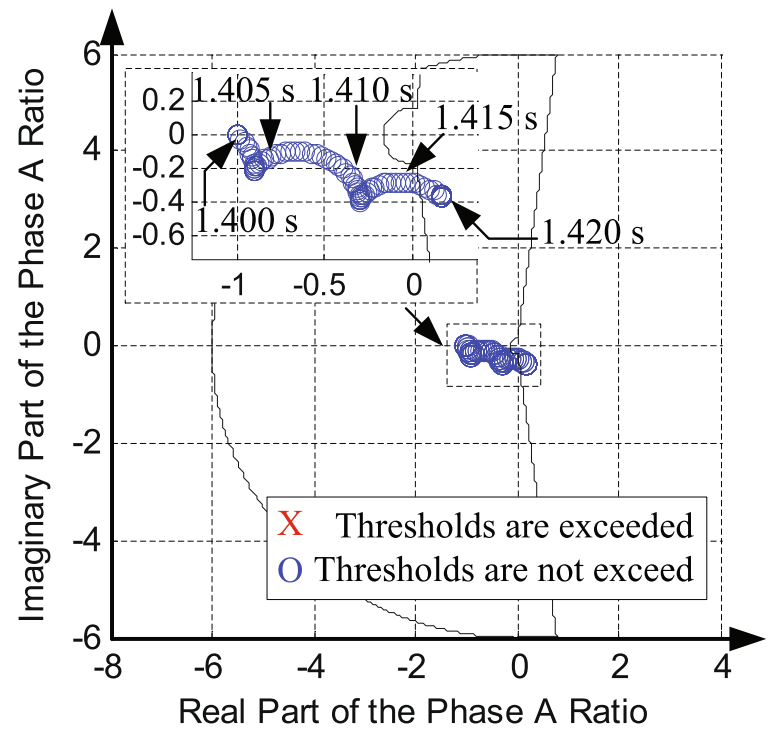

Fig. 10 Calculated current phasor ratio trance of event 2: internal high impedance fault, grid-connected mode 


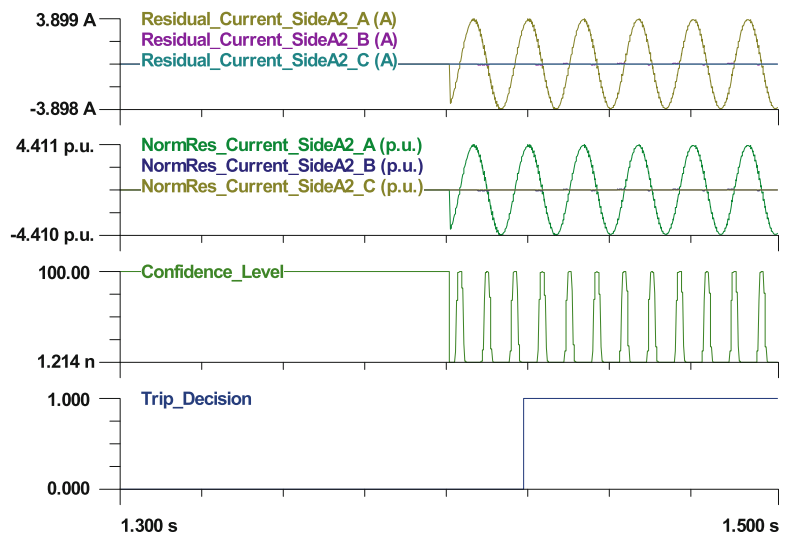

Fig. 11 EBP relay performance of event 2: internal high impedance fault, grid-connected mode

relay trips this internal fault with delay at $1.5696 \mathrm{~s}$ $(1.4196 \mathrm{~s}+0.15 \mathrm{~s})$.

\subsubsection{Line differential relay}

The trace of the zero-sequence current phasor ratio, superimposed on the relay characteristics, is shown in Fig. 18. Prior to the fault, the ratio stays close to $(-1,0)$ with no threshold exceeded. During the fault, the ratio enters the trip region at $1.4014 \mathrm{~s}$, with thresholds exceeded. Therefore, the line differential protection trips the circuit at $1.4181 \mathrm{~s}(1.4014 \mathrm{~s}+1$ cycle of $0.0167 \mathrm{~s})$.

\subsubsection{EBP relay}

The performance of the EBP relay is depicted in Fig. 19. The first two channels demonstrate the residuals and the normalized residuals of the three-phase currents at side A2, respectively. It can be observed that the residuals are small before the fault but become extremely large during the fault. The confidence level in the third channel drops to zero one sample after the fault

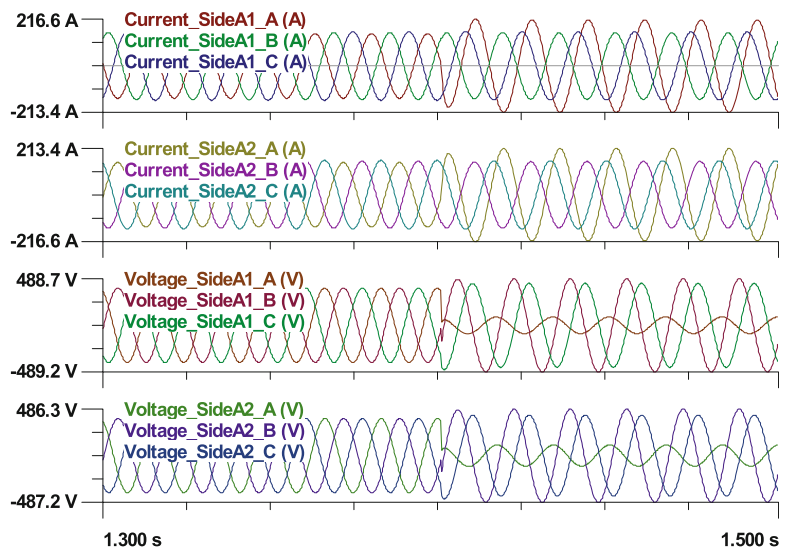

Fig. 12 Three phase currents and voltages of event 3: external bolted fault, grid-connected mode

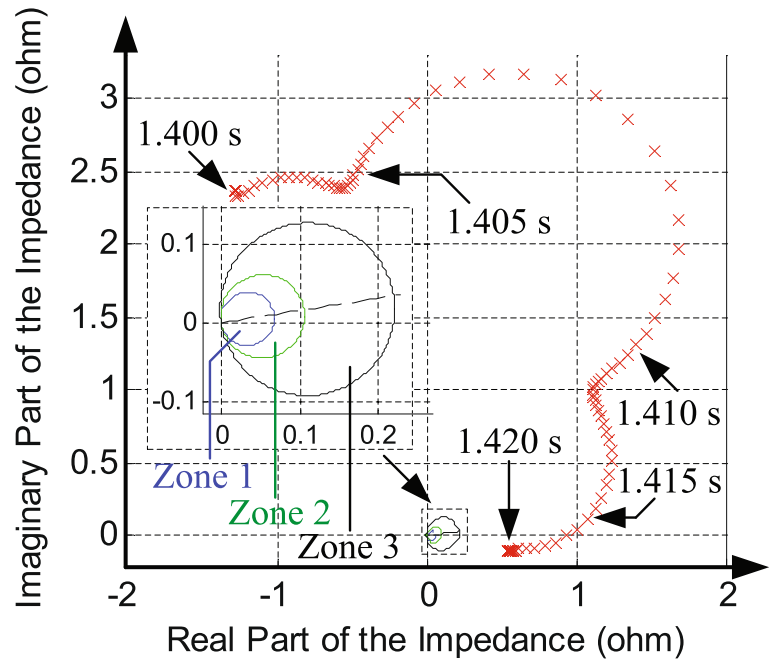

Fig. 13 Calculated impedance trace of event 3: external bolted fault, grid-connected mode

occurrence. The fault is thus detected at $1.4002 \mathrm{~s}$ and the circuit is tripped (in the fourth channel) at $1.4169 \mathrm{~s}$.

\subsubsection{Summary of event 4}

For this internal bolted phase A to ground fault during the islanded mode, the distance relay detects the fault at $1.4196 \mathrm{~s}$ and trips the circuit at $1.5696 \mathrm{~s}$, whereas the line differential relay detects the fault at $1.4014 \mathrm{~s}$ and trips the circuit at $1.4181 \mathrm{~s}$. For the EBP relay, the fault is detected at $1.4002 \mathrm{~s}$ and the circuit is tripped faster than both legacy relays at $1.4169 \mathrm{~s}$.

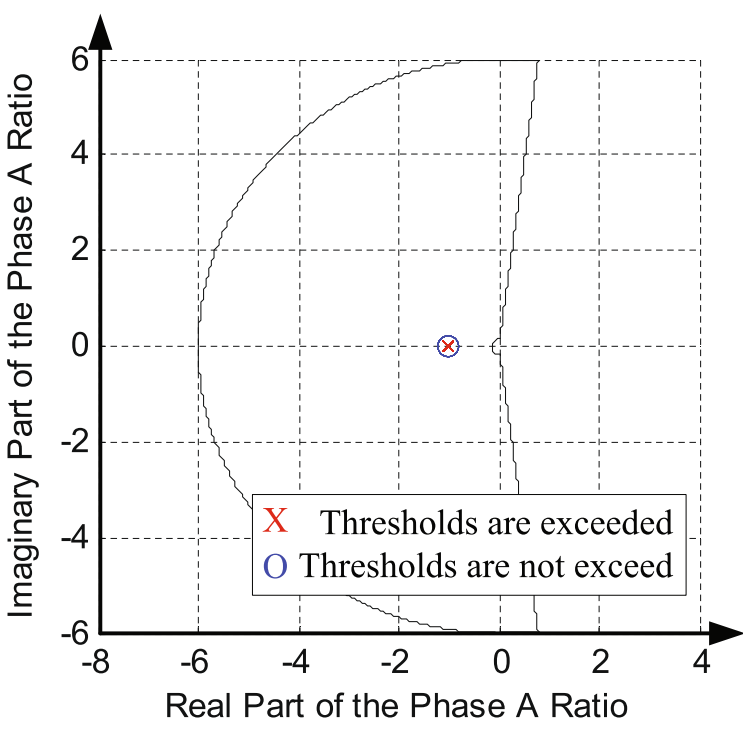

Fig. 14 Calculated current phasor ratio trance of event 3: external bolted fault, grid-connected mode 


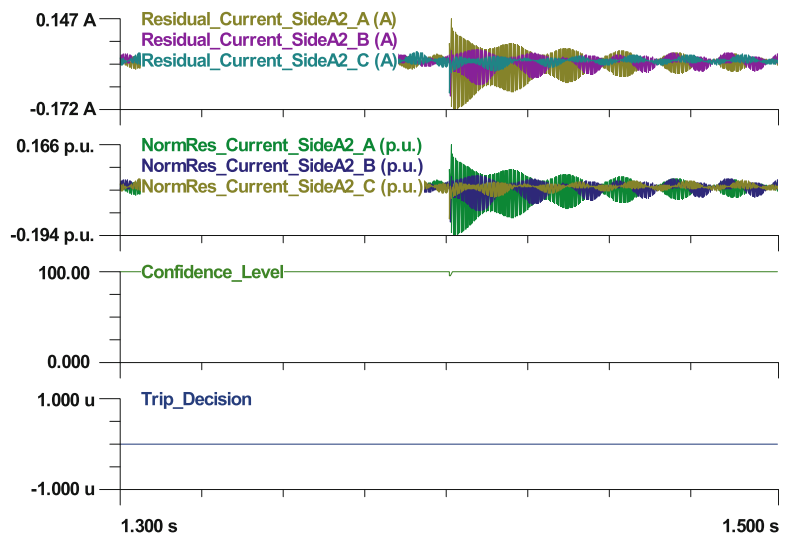

Fig. 15 EBP relay performance of event 3: external bolted fault, grid-connected mode

\subsubsection{Event 5: Internal high impedance fault, grid- connected mode, with $1 \%$ random error}

A high impedance $(50 \Omega)$ phase A to ground fault occurs in the middle of A1-A2 at $1.4 \mathrm{~s}$. This event is the same as event 2 except that the three-phase currents and voltages at both sides of line A1-A2 are added with $1 \%$ random error. The three-phase currents and voltages at both sides of A1-A2 are similar to those in Fig. 8.

\subsubsection{Distance relay}

The calculated impedance trace is similar to that in Fig. 9 and the distance relay fails to detect this internal fault.

\subsubsection{Line differential relay}

The trace of the zero-sequence current phasor ratio is similar to that in Fig. 10 and the line differential protection also fails to detect this internal fault.

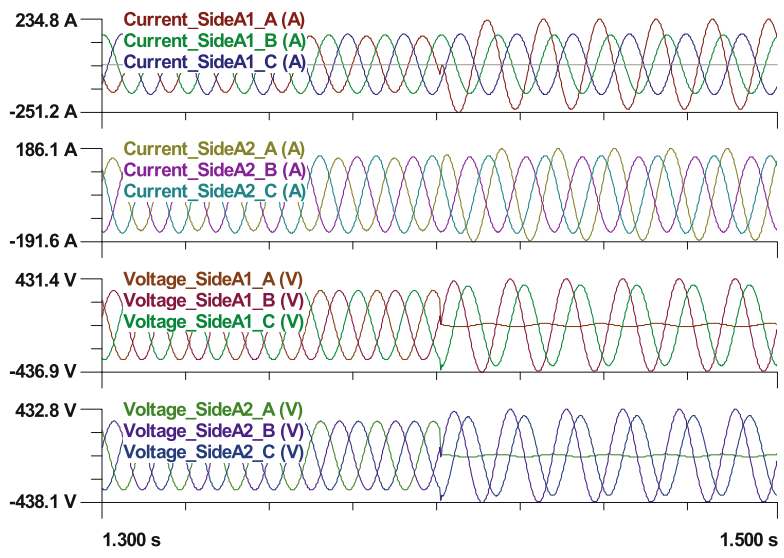

Fig. 16 Three phase currents and voltages of event 4: internal bolted fault, islanded mode

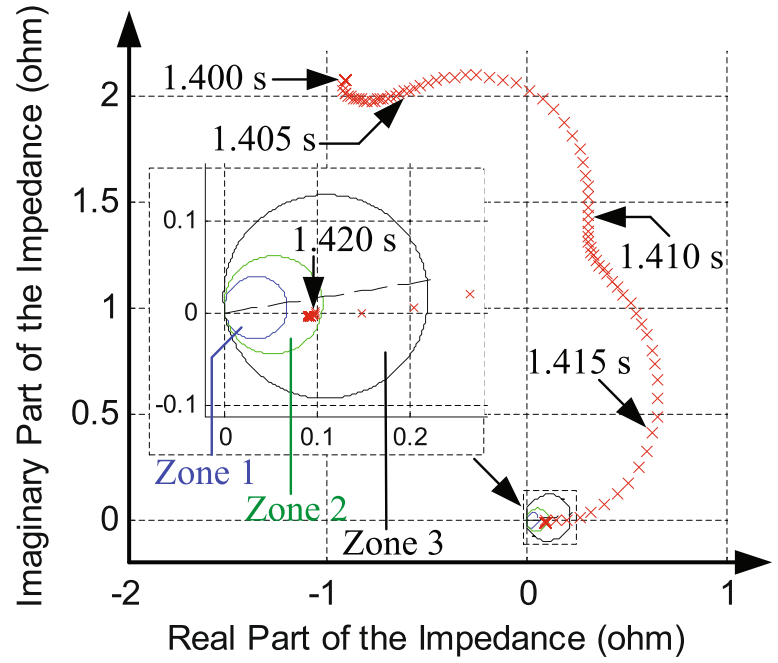

Fig. 17 Three phase currents and voltages of event 4: internal bolted fault, islanded mode

\subsubsection{EBP relay}

The performance of the EBP relay is depicted in Fig. 20. Prior to the fault, the confidence level remains at a relatively high level. During the fault, the confidence level drops to zero one sample after fault occurrence and oscillates during the fault, indicating abnormality of the circuit. The fault is detected at $1.4002 \mathrm{~s}$ and the circuit is tripped at $1.4183 \mathrm{~s}$.

\subsubsection{Summary of event 5}

For this internal high impedance phase A to ground fault during the grid-connected mode with added $1 \%$ random error, both the distance relay and line

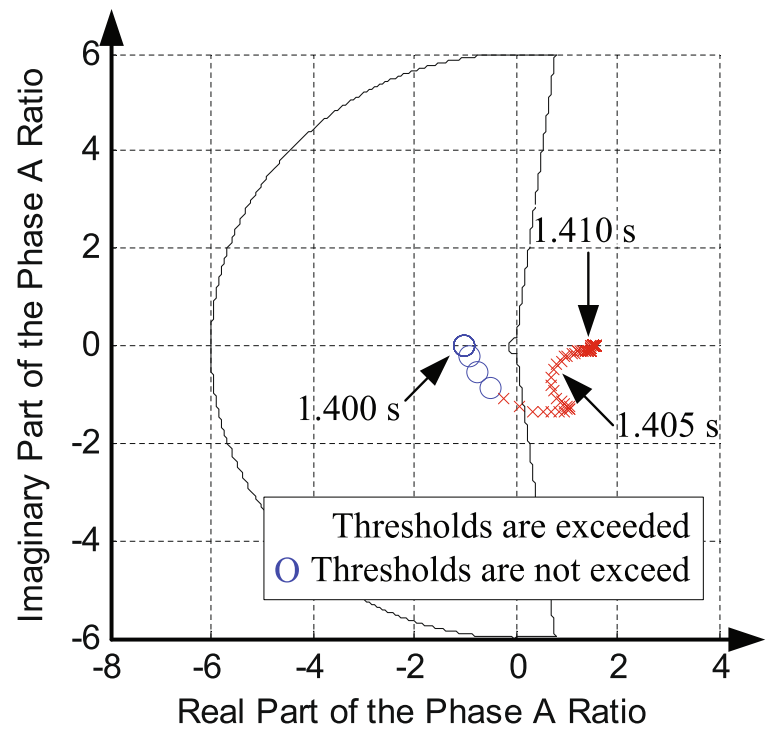

Fig. 18 Calculated current phasor ratio trance of event 4: internal bolted fault, islanded mode 


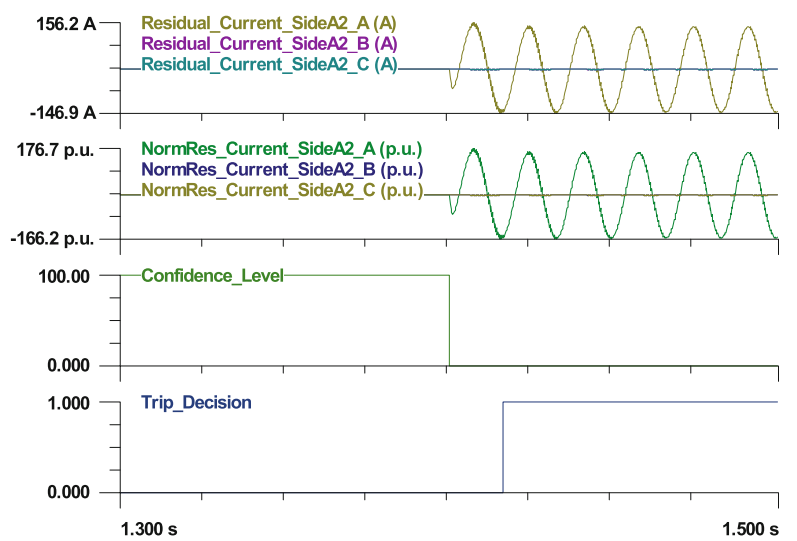

Fig. 19 EBP relay performance of event 4: internal bolted fault, islanded mode

differential relay fail to detect this internal fault, whereas the EBP relay detects the fault at $1.4002 \mathrm{~s}$ and trips the line at $1.4183 \mathrm{~s}$.

\subsection{CIG control}

The example test system is a $34.5 \mathrm{kV} \mu \mathrm{Grid}$ provided in Fig. 21. The $\mu$ Grid is connected to the main grid with a static switch at the point of common coupling and a $230 \mathrm{kV} / 34.5 \mathrm{kV}$ transformer. The series resistance, series reactance and shunt capacitance matrices per unit length of the $\mu$ Grid circuit are shown in Table 4. There are three CIGs inside the $\mu$ Grid, including two PV systems and a Wind Turbine System (WTS). To demonstrate the performance of the proposed CIG control scheme via the WTS, its controller ensures the local side phase angle (side L of the $34.5 \mathrm{kV}$ transmission line LR) to follow the change of the remote phase angle (side $\mathrm{R}$ of the $34.5 \mathrm{kV}$ transmission line LR). To achieve the above goal, the DSE algorithm based on AQCF syntax is utilized to accurately estimate the remote side frequency

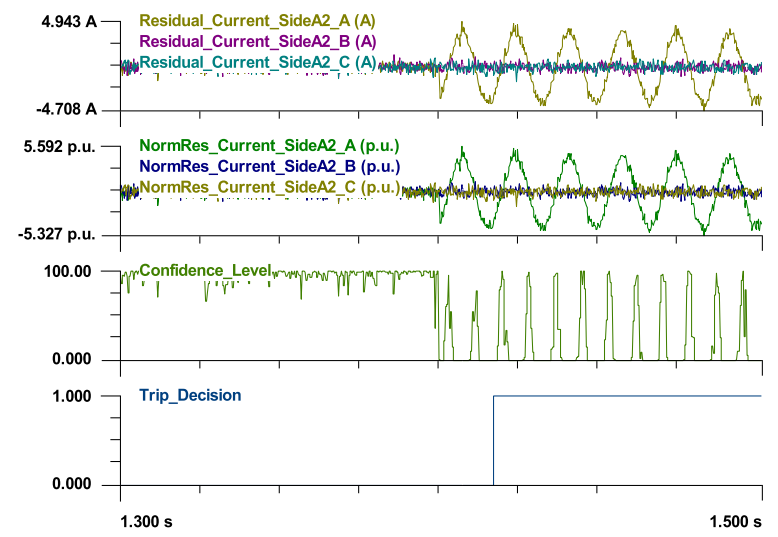

Fig. 20 EBP relay performance of event 5: internal high impedance fault, grid-connected mode, $1 \%$ random error

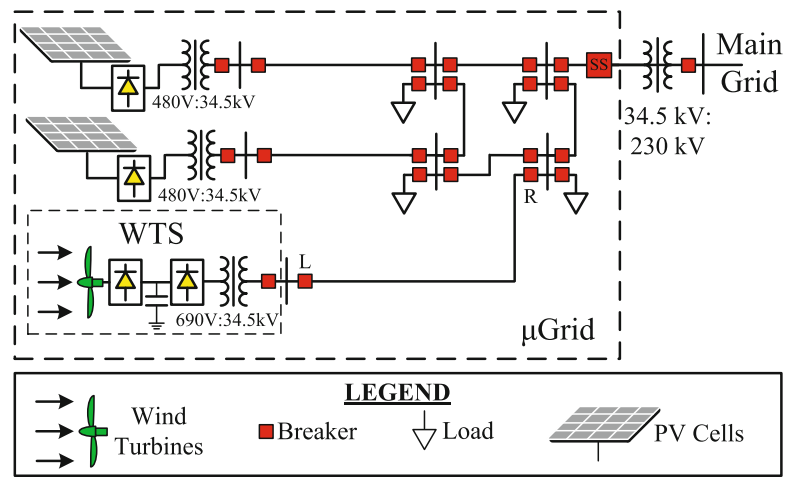

Fig. 21 Example System of CIG Control

and rate of frequency change based on local information only. Note that in this simulation, intentional disturbances are introduced to generate frequency oscillations inside the $\mu$ Grid.

\subsection{Remote side frequency estimation}

The simulation results of the remote side frequency estimation with local information only are provided in Fig. 22. The measurements are the three-phase currents and voltages at the local side (side L). Note that the length of the $34.5 \mathrm{kV}$ line LR is 2.5 miles. As shown in Fig. 22, the first two channels depict the actual and estimated three-phase voltages at the remote side of the line LR. The third and fourth channels provide the actual and estimated frequencies, and the estimation error, respectively. It can be observed that the estimation error of the frequency is within $-9.464 \times$ $10^{-5} \sim 2.82 \times 10^{-4} \mathrm{~Hz}$. The actual and estimated rates of frequency change, and the estimation error are shown in the fifth and sixth channels, respectively. As seen, the estimation error of the rate of the frequency change is within $-1.906 \times 10^{-3} \sim 1.689 \times 10^{-3} \mathrm{~Hz} / \mathrm{s}$.

Table 4 Series resistance, series reactance and shunt capacitance matrices of the $34.5 \mathrm{kV} \mu \mathrm{Grid}$ circuit

\begin{tabular}{|c|c|c|c|c|c|c|}
\hline Parameter & Value & & & & & \\
\hline $\begin{array}{l}\text { Series resistance } \\
\text { matrix (per mile) }\end{array}$ & {$\left[\begin{array}{l}0.1818 \\
0.0924 \\
0.0924 \\
0.0922\end{array}\right.$} & $\begin{array}{ll}0.0924 \\
0.1818 \\
0.0924 \\
0.0922\end{array}$ & $\begin{array}{l}0.0924 \\
0.0924 \\
0.1818 \\
0.0922\end{array}$ & $\left.\begin{array}{l}0.0922 \\
0.0922 \\
0.0922 \\
0.1818\end{array}\right]$ & $\Omega / m i$ & \\
\hline $\begin{array}{l}\text { Series reactance } \\
\text { matrix (per mile) }\end{array}$ & {$\left[\begin{array}{l}3.5842 \\
2.1146 \\
2.1146 \\
1.9353\end{array}\right.$} & $\begin{array}{l}2.1146 \\
3.5842 \\
1.8918 \\
1.8802\end{array}$ & $\begin{array}{l}2.1146 \\
1.8918 \\
3.5842 \\
1.8992\end{array}$ & $\left.\begin{array}{l}1.9353 \\
1.8802 \\
1.8992 \\
3.5842\end{array}\right]$ & $\mathrm{mH} / \mathrm{m}$ & \\
\hline $\begin{array}{l}\text { Shunt capacitance } \\
\text { matrix (per mile) }\end{array}$ & {$\left[\begin{array}{c}8.4066 \\
-2.3555 \\
-2.3417 \\
-1.0823\end{array}\right.$} & $\begin{array}{c}-2.3555 \\
7.7689 \\
-1.1427 \\
-1.0362\end{array}$ & $\begin{array}{lr}5 & -2.341 \\
& -1.142 \\
7 & 7.794 \\
2 & -1.105\end{array}$ & $\begin{array}{cc}17 & -1 . \\
27 & -1 . \\
43 & -1 . \\
56 & 5.6\end{array}$ & $\left.\begin{array}{l}.0823 \\
.0362 \\
.1056 \\
6988\end{array}\right]$ & $n F / m i$ \\
\hline
\end{tabular}




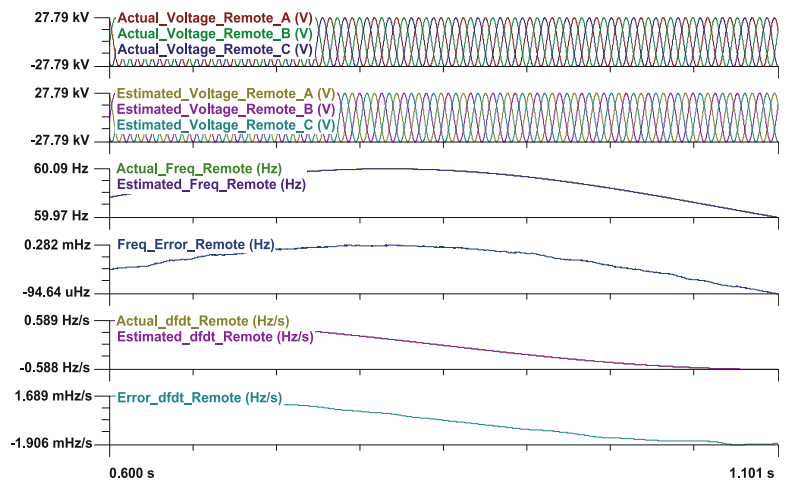

Fig. 22 Estimation results of frequency and the rate of frequency change based on DSE

To further validate the accuracy of the frequency estimation algorithm, further studies are conducted with different lengths of line LR and the results are shown in Table 5. It can be seen that the frequency estimation error is higher for longer lines though the estimation is still very accurate (maximum absolute error of $4.51 \times$ $10^{-4} \mathrm{~Hz}$ for frequency and $2.896 \times 10^{-3} \mathrm{~Hz} / \mathrm{s}$ for the rate of frequency change).

\subsection{CIG control}

The estimate frequency and the rate of frequency change are utilized as feedback signals to control the output of the CIG. Traditional local information based control scheme utilizes P-f and Q-V droop control, however, the proposed DSE based control scheme is based on P-Q mode and utilizes the estimated remote side frequency as the frequency input. The references of the real and reactive power are $2 \mathrm{MW}$ and $0.5 \mathrm{MVar}$, respectively. Figure 23 shows the output of the CIG with the traditional local information based control scheme and the proposed DSE based control scheme. The first two channels depict the real power outputs from both schemes, while the third and fourth channels provide the reactive power outputs from both schemes. The fifth and sixth channels show the local and remote phase angles of both schemes.

With the traditional local information based control scheme, the real and reactive power outputs, the power factor and the phase angle difference oscillate. In this case, the CIG may exceed the desirable operation

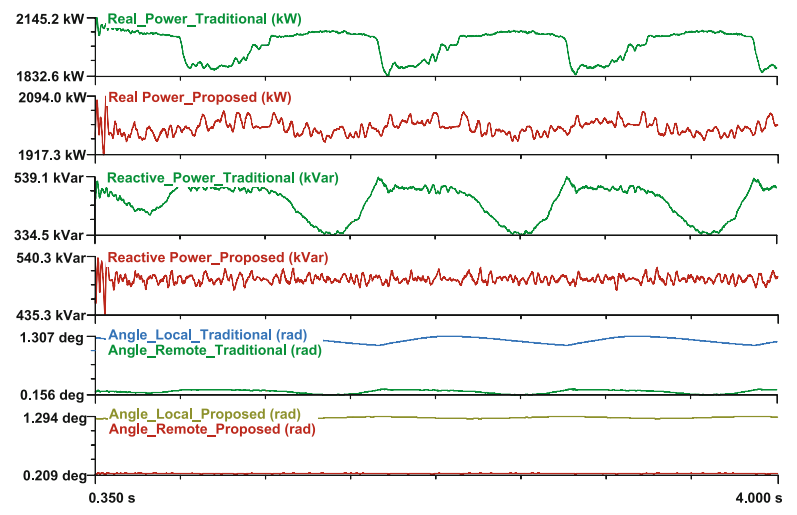

Fig. 23 Output of the CIG during disturbances with the traditional local information based and the proposed DSE based control scheme

constraints potentially causing damage or leading to the shutdown of the CIG. With the proposed control scheme, the oscillation of the real and reactive power is significantly reduced. In addition, the power factor is kept within the operation constraint and the phase angle difference is stable. Therefore, undesirable transients are successfully minimized by the proposed control scheme.

\section{Conclusion}

Converter Interfaced Generations (CIGs) bring significant challenges in $\mu$ Grid protection and CIG control. This paper proposes a Dynamic State Estimation (DSE) based algorithm using high-fidelity dynamic models and sampled value measurements for dependable and secure protection and control of $\mu$ Grid systems. For the protection application, the DSE based protection algorithm detects internal faults by checking any inconsistency between the measurements and the model. The advantages of the proposed protection scheme include: (a) detection of internal faults faster than legacy schemes; (b) improved sensitivity towards high impedance faults; (c) satisfactory performance in $\mu$ Grid protection in both grid-connected mode and islanded mode; and (d) working correctly during non-ideal conditions such as measurements with added 1\% random error. For CIG control application, the DSE provides accurate estimation of the remote

Table 5 Estimation error of frequency and rate of frequency change with different lengths of the line

\begin{tabular}{lll}
\hline Line length & Frequency error & dFreq/dt error \\
\hline 1.5 miles & $-6.513 \times 10^{-5} \sim 1.77 \times 10^{-4} \mathrm{~Hz}$ & $-1.144 \times 10^{-3} \sim 1.049 \times 10^{-3} \mathrm{~Hz} / \mathrm{s}$ \\
2.5 miles & $-9.464 \times 10^{-5} \sim 2.82 \times 10^{-4} \mathrm{~Hz}$ & $-1.906 \times 10^{-3} \sim 1.689 \times 10^{-3} \mathrm{~Hz} / \mathrm{s}$ \\
4 miles & $-1.29 \times 10^{-4} \sim 4.51 \times 10^{-4} \mathrm{~Hz}$ & $-2.896 \times 10^{-3} \sim 2.751 \times 10^{-3} \mathrm{~Hz} / \mathrm{s}$ \\
\hline
\end{tabular}


side frequency as well as the rate of frequency change from local information only, which can then be used to provide supplementary feedback control to the converters of the CIG. The advantages of the proposed control scheme include: (a) no need for communication from remote sides; (b) accurate estimation of the remote side frequency and rate of frequency change based on local information; and (c) minimizing the CIG output oscillation during system disturbances.

\section{Appendix}

\section{$5.1 \mu$ Grid circuit model (cable)}

This Appendix describes the model of $\mu$ Grid circuit (cable) in QDM syntax. Note that here a multi-section model is adopted, where each section is a $\pi$-equivalent model of the cable. The length of each section is selected to make sure that it is comparable to the traveling length of electromagnetic wave during one sampling interval. The overall QDM of any $\mu$ Grid circuit can be obtained by mathematically combining QDMs of all sections. Figure 24 shows a $\pi$-equivalent model of a circuit section with the cable structure in Fig. 3.

The model of the above section in QDM syntax is,

$$
\begin{aligned}
& \mathbf{i}(t)=\left[\begin{array}{llll}
\mathbf{i}_{a 1}(t) & \mathbf{i}_{b 1}(t) & \mathbf{i}_{c 1}(t) & \mathbf{i}_{n 1}(t) \\
\mathbf{i}_{a 2}(t) & \mathbf{i}_{b 2}(t) & \mathbf{i}_{c 2}(t) & \mathbf{i}_{n 2}(t)
\end{array}\right]^{\mathrm{T}}
\end{aligned}
$$

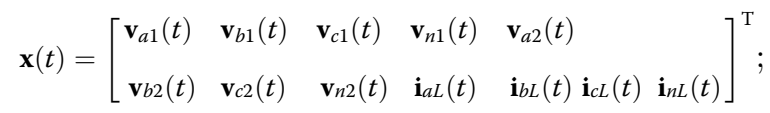

$$
\begin{aligned}
& \mathbf{Y}_{e q x 1}=\left[\begin{array}{ccc}
\mathbf{0} & \mathbf{0} & \mathbf{I}_{4} \\
\mathbf{0} & \mathbf{0} & -\mathbf{I}_{4}
\end{array}\right] ; \mathbf{D}_{e q x 1}=\left[\begin{array}{ccc}
\mathbf{C} & \mathbf{0} & \mathbf{0} \\
\mathbf{0} & \mathbf{C} & \mathbf{0}
\end{array}\right] \\
& \mathbf{Y}_{e q x 2}=\left[\begin{array}{lll}
-\mathbf{I}_{4} & \mathbf{I}_{4} & \mathbf{R}
\end{array}\right] ; \mathbf{D}_{e q x 2}=\left[\begin{array}{lll}
\mathbf{0} & \mathbf{0} & \mathbf{L}
\end{array}\right] ;
\end{aligned}
$$

all other vectors / matrices are null;

where $\mathbf{i}_{a 1}(t), \mathbf{i}_{b 1}(t), \mathbf{i}_{c 1}(t), \mathbf{i}_{n 1}(t), \mathbf{i}_{a 2}(t), \mathbf{i}_{b 2}(t), \mathbf{i}_{c 2}(t)$ and $\mathbf{i}_{n 2}(t)$ are the three-phase and neutral currents at both terminals of the section; $\mathbf{v}_{a 1}(t), \mathbf{v}_{b 1}(t), \mathbf{v}_{c 1}(t), \mathbf{v}_{n 1}(t), \mathbf{v}_{a 2}(t)$, $\mathbf{v}_{b 2}(t), \mathbf{v}_{c 2}(t)$ and $\mathbf{v}_{n 2}(t)$ are the three-phase and neutral voltages at both terminals of the section; $\mathbf{i}_{a L}(t), \mathbf{i}_{b L}(t)$,

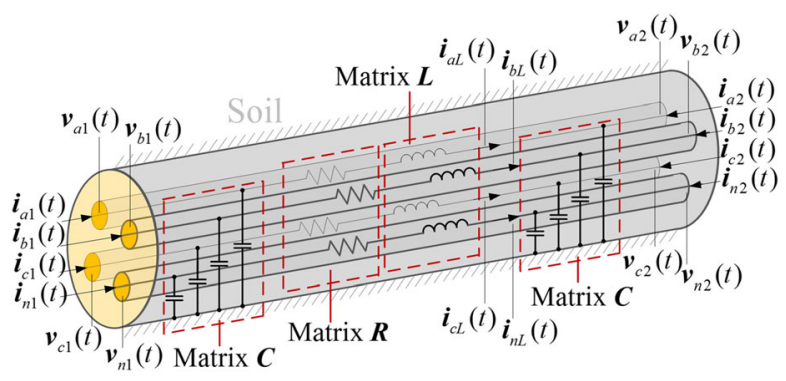

Fig. 24 m-equivalent model of a circuit section (mutual inductances and capacitances are not shown) $\mathbf{i}_{c L}(t)$ and $\mathbf{i}_{n L}(t)$ are the three-phase and neutral currents through inductors; $\mathbf{R}, \mathbf{L}$ and $\mathbf{C}$ are series resistance, series inductance, and shunt capacitance matrices of the section. Note that matrices $\boldsymbol{R}, \boldsymbol{L}$ and $\boldsymbol{C}$ are accurately calculated from the physical structure and environmental condition of the cables.

\section{Funding}

This work is supported by Electric Power Research Institute (EPRI). Its support is greatly appreciated.

\section{Availability of data and materials}

Please contact author for data requests.

\section{Authors' contributions}

$Y L$ carried out the dynamic state estimation based protection scheme, the dynamic state estimation based converter control scheme and drafted the manuscript. APM participated in the design and coordination of the study and helped to draft the manuscript. LS participated in the implementation of both the protection and the converter control schemes, and helped to draft the manuscript. SC participated in the implementation of the converter control scheme and helped to draft the manuscript. All authors read and approved the final manuscript.

\section{Competing interests}

The authors declare that they have no competing interests.

\section{Author details}

${ }^{1}$ School of Information Science and Technology (SIST), ShanghaiTech University, Shanghai 201210, China. ${ }^{2}$ School of Electrical and Computer Engineering (ECE), Georgia Institute of Technology, Atlanta, GA 30332, USA.

Received: 16 October 2017 Accepted: 11 September 2018

Published online: 18 October 2018

References

1. Lasseter, R. H. (2002). Microgrids. In Proc. IEEE power engineering society winter meeting (Vol. 1, pp. 305-308).

2. Hatziargyriou, N., Asano, H., Iravani, R., \& Marnay, C. (2007). Microgrids. IEEE Power and Energy Magazine, 5(4), 78-94.

3. Blaabjerg, F., \& Ma, K. (2013). Future on power electronics for wind turbine systems. IEEE Journal of Emerging and Selected Topics in Power Electronics, $1(3), 139-152$.

4. Ustun, T. S., Ozansoy, C., \& Ustun, A. (2013). Fault current coefficient and time delay assignment for microgrid protection system with central protection unit. IEEE Transactions on Power Systems, 28(2), 598-606.

5. Zamani, M. A., Sidhu, T. S., \& Yazdani, A. (2011). A protection strategy and microprocessor-based relay for low-voltage microgrids. IEEE Transactions on Power Delivery, 26(3), 1873-1883.

6. Sortomme, E., Venkata, S. S., \& Mitra, J. (2010). Microgrid protection using communication-assisted digital relays. IEEE Transactions on Power Delivery, 25(4), 2789-2796.

7. Samantaray, S. R., Joos, G., \& Kamwa, I. (2012). Differential energy based microgrid protection against fault conditions. In IEEE PES Innovative Smart Grid Technologies (ISGT), Washington, DC (pp. 1-7).

8. Miao, L., Wen, J., Xie, H., Yue, C., \& Lee, W. J. (2015). Coordinated control strategy of wind turbine generator and energy storage equipment for frequency support. IEEE Transactions on Industry Applications, 51(4), 2732-2742.

9. Gonzalez-Longatt, F. M. (2015). Activation schemes of synthetic inertia controller on full converter wind turbine (type 4). In IEEE power and energy society general meeting (pp. 1-5).

10. Lalor, G., Mullane, A., \& O'Malley, M. (2005). Frequency control and wind turbine technologies. IEEE Transactions on Power Systems, 20(4), 1905-1913.

11. Arani, M. F. M., \& El-Saadany, E. F. (2013). Implementing virtual inertia in DFIG-based wind power generation. IEEE Transactions on Power Systems, 28(2), 1373-1384.

12. Baran, M. E., \& Mahajan, N. R. (2007). Overcurrent protection on voltagesource-converter-based multiterminal DC distribution systems. IEEE Transactions on Power Delivery, 22(1), 406-412. 
13. Blaabjerg, F., Teodorescu, R., Liserre, M., \& Timbus, A. V. (2006). Overview of control and grid synchronization for distributed power generation systems. IEEE Transactions on Industrial Electronics, 53(5), 1398-1409.

14. Agirman, I., \& Blasko, V. (2003). A novel control method of a VSC without AC line voltage sensors. IEEE Transactions on Industry Applications, 39(2), 519-524.

15. Teodorescu, R., \& Blaabjerg, F. (2004). Flexible control of small wind turbines with grid failure detection operating in stand-alone and grid-connected Mode. IEEE Transactions on Power Electronics, 19(5), 1323-1332.

16. Liu, Y., Meliopoulos, S., Fan, R., Sun, L., \& Tan, Z. (2017). Dynamic state estimation based protection on series compensated transmission lines. IEEE Transactions on Power Delivery, 32(5), 2199-2209.

17. Meliopoulos, S., Cokkinides, G. J., Myrda, P., Liu, Y., et al. (2017). Dynamic state estimation based protection: status and promise. IEEE Transactions on Power Delivery, 32(1), 320-330.

18. Liu, Y., Meliopoulos, S., Tan, Z., Sun, L., \& Fan, R. (2017). Dynamic state estimation-based fault locating in transmission lines. IET Generation Transmission and Distribution, 11(17), 4184-4192.

19. Meliopoulos, A. P., Cokkinides, G. J., \& Stefopoulos, G. K. (2005). Quadratic integration method. In Int. Power Syst. Transients (IPST) Conf., Montreal, Canada.

20. (2011). SEL-387L relay instruction manual. Pullman: Schweitzer Engineering Laboratories, Inc.

\section{Submit your manuscript to a SpringerOpen ${ }^{\circ}$ journal and benefit from:}

- Convenient online submission

- Rigorous peer review

- Open access: articles freely available online

High visibility within the field

- Retaining the copyright to your article

Submit your next manuscript at $\boldsymbol{\nabla}$ springeropen.com 